\title{
Anti-Xa Activity International Unit per Milliliter
}

National Cancer Institute

\section{Source}

National Cancer Institute. Anti-Xa Activity International Unit per Milliliter. NCI Thesaurus. Code C70498.

A specific anticoagulation activity of unfractionated or low molecular weight heparin on factor Xa, expressed as a number of international anti-Xa heparin units per one milliliter of plasma. 